\title{
A IMPOSIÇÃO DO REGIME DE SEPARAÇÃO DE BENS AOS NUBENTES SEPTUAGENÁRIOS FACE AO PRINCÍPIO DA DIGNIDADE DA PESSOA HUMANA
}

\author{
Mariana Campos Matoso*
}

\section{RESUMO}

O presente artigo tem o objetivo de abordar a imposição do regime de separação legal de bens na perspectiva contemporânea, considerando os princípios da Constituição Federal de 1988 e o Estatuto do Idoso, com considerações sobre a expectativa de vida e o envelhecimento no Brasil, bem como entendimento doutrinário, jurisprudencial e outras conceituações pertinentes. A metodologia utilizada na pesquisa é a indutiva, com pesquisa bibliográfica por coleta de dados literários, artigos, e dispositivos legais. Com o resultado verifica-se a necessidade de revogação da norma que impõe o regime de separação obrigatória de bens aos maiores de 70 anos de idade.

PALAVRAS-CHAVE: código civil; constituição; dignidade da pessoa humana; inconstitucionalidade; regime de bens; septuagenário.

\section{THE IMPOSITION OF THE REGIME OF SEPARATION OF ASSETS TO SEPTUAGENARIANS IN VIEW OF THE PRINCIPLE OF HUMAN DIGNITY}

\begin{abstract}
This article aims to address the imposition of the legal separation of property regime, in a contemporary perspective, considering the principles of the Federal Constitution of 1998 and the Elderly Statute, with considerations on life expectancy and aging in Brazil, as well as doctrinal understanding, jurisprudence and Other pertinente concepts. The medhodology used in the research is inductive, with bibliographic research by collecting literary data, articles, and legal provisions. As a result, there is a need to repeal the rule that imposes the mandatory separation of goods regime for people over 70 years of age.
\end{abstract}

KEY WORDS: civil code; constitution; dignity of human person; unconstitutionality; property regime; septuagenarian

\section{1 - INTRODUÇÃO}

Este artigo inicia com breves considerações sobre o a conceituação de regime de bens, aprofundando um pouco mais na conceituação do regime de separação legal de bens, que é o objeto desse trabalho. Foi analisada a imposição do regime de separação obrigatória aos nubentes septuagenários.

\footnotetext{
* Mestranda em Proteção dos Direitos Fundamentais pela Universidade de Itaúna. Graduada em Direito pelas Faculdades Integradas Pitágoras de Montes Claros, Pós-graduada em Direito Civil pela PUC Minas.
} 
Foi feita, também, considerações sobre a afronta a princípios constitucionais, especial o princípio da dignidade humana como fundamento do Estado Democrático de Direito expresso no Art. I ${ }^{\circ}$, Inc. III, da Constituição Federal do Brasil e no Art. $2^{\circ}$ do Estatuto do Idoso.

Atentando, ainda, para o fato que passamos por inúmeras mudanças sociais, inclusive a modificação na estrutura das famílias, avanços tecnológicos, que implicou profundas transformações possibilitando ao ser humano desfrutar a cada dia uma melhor qualidade de vida e por consequência experimentar uma maior expectativa de vida, sendo assim, a população idosa do Brasil está em evidente crescimento.

Em seguida, passa-se a uma breve consideração sobre a inconstitucionalidade da norma e do entendimento do STF, com a súmula 377, sobre o tema.

Por fim, foram apresentadas conclusões pontuais acerca do tema abordado, concluindo até que ponto pode se considerar constitucional a imposição do regime de bens aos septuagenários, disposto no Art. 1.641 do Código Civil, considerando que, aparentemente, há uma inobservância dos princípios previstos na Constituição Federal, com base na referência bibliográfica que amparou a pesquisa.

O método utilizado para a realização do trabalho foi o indutivo com a abordagem de categorias consideradas fundamentais para o desenvolvimento do tema. Os procedimentos técnicos utilizados na pesquisa para coleta de dados foram essencialmente a pesquisa bibliográfica para responder a pergunta-problema: se o idoso goza de todos os direitos fundamentais inerentes à pessoa humana, por que não lhe é assegurado o direito de escolha ao tipo de regime de bens?

A base teórica da pesquisa foi o levantamento bibliográfico, baseando-se nas doutrinas, obras, e textos de autores de referência. As principais fontes desta pesquisa são a bibliografia que norteia a análise da legislação.

\section{2- REGIME DE BENS}

O casamento implica em comunhão de vida, tendo dupla função, pois a comunhão não é apenas pessoal, mas também patrimonial. A comunhão plena de vida, que é o objetivo do matrimonio, sendo um reflexo das vontades dos contraentes partilhar a vida. Ocorre que, a comunhão no aspeto patrimonial pode ser limitada, de acordo com o regime de bens escolhido pelos nubentes. 
É importante que o casal antes da constituição familiar, pondere acerca das características patrimoniais, e escolham de forma consciente o regime de bens mais adequando para sua família.

A família é a base da sociedade necessitando de proteção do estado, de acordo com a Constituição Federal, artigo 226, nesse sentido o Código Civil dispõe em seu artigo 1511 que "O casamento estabelece comunhão plena de vida.", a regulação da comunhão de interesses patrimoniais foi feita pela lei civil através dos regimes de bens.

O regime de bens, apesar de ligado a questões patrimoniais, deve ser pautado nos princípios constitucionais, como por exemplo a dignidade da pessoa humana, além de respeitar o principio norteador da relação civil que é a autonomia privada.

Doutrinariamente existem várias conceituações para o regime de bens como a de Cristiano Chaves de Farias e Nelson Rosenvald (2011, p. 272), que dizem:

[...] é o estatuto que disciplina os interesses econômicos, ativos e passivos, de um casamento, regulamentando as consequências em relação aos próprios nubentes e a terceiros, desde a celebração até a dissolução do casamento, em vida ou por morte

Nesse seguimento Orlando Gomes, define regime de bens como sendo o "estatuto patrimonial dos cônjuges", compreendendo, assim, "as relações patrimoniais entre os cônjuges e entre terceiros e a sociedade conjugal" (GOMES, 2011, p. 272). Sintetiza, também, Maria Berenice Dias (2010, p.220) o conceito de regime de bens como sendo:

O regime de bens é uma das consequências jurídicas do casamento. A bem da verdade, não existe casamento sem regime patrimonial de bens. Se os nubentes não escolhem, há uma "escolha" da lei pelo regime legal. É impositiva alguma espécie de regramento de ordem patrimonial. Quando não há a imposição legal do regime da separação, abstendo-se os nubentes de eleger um regime de bens, o Estado faz a opção por eles do regime da comunhão parcial. Aos noivos basta pronunciar o "sim" na solenidade do matrimônio. Essa afirmativa, além de significar múltipla aceitação do casal, faz incidir um sem-número de regras, assegura direitos e impõe deveres. A escolha do regime de bens, feita por ocasião do casamento, rege a situação patrimonial durante a vigência do matrimônio e, principalmente, quando de sua dissolução, pela separação, divórcio ou morte de um dos consortes.

Vale registrar, ainda, a conceituação dada por Flávio Tartuce (2012, p.1078-1079), que define o regime matrimonial de bens como sendo "o conjunto de regras de ordem privada relacionadas com interesses patrimoniais ou econômicos resultantes da entidade familiar".

A Constituição Federal, em seus arts. $1^{\circ}$, IV, e 170 promove a livre iniciativa, especialmente quando é prevista a liberdade contratual, além do que seu art. $5^{\circ}$, II, serve também como fundamento constitucional da autonomia da vontade. George Marmelstein (2013, p. 102) relata que mesmo a Constituição Brasileira sendo "tão generosa ao proclamar direitos", não há "nenhum dispositivo que consagre claramente o direito à autonomia 
privada", mas menciona, como "fonte normativa para a proteção da autonomia da vontade, o art. 5, II". A partir da Constituição Federal de 1988, diversas mudanças ocorreram, passou-se a tratar de direitos fundamentais nas relações privadas, o que significa tratar da eficácia horizontal dos direitos fundamentais, o que possibilitou que a família tomasse novas formas preocupando-se mais com o respeito a princípios como a dignidade.

Estão expressamente previstos no Subtítulo I do Título II do Livro V (Do Direito De Família) do Código Civil, os regimes de bens, especificamente entre os artigos 1639 e 1688.

$\mathrm{Na}$ lei civil brasileira há disposição, do regime de comunhão parcial entre os artigos 1658 e1666; do regime da comunhão universal de bens entre os artigos 1667 e 1671; do regime da participação final nos aquestos dos artigos 1672 a 1686 e o regime da separação convencional de bens nos artigos 1687 e 1688, por fim a separação legal de bens encontra-se regulada no artigo 1641.

Além das disposições específicas para os diversos regimes de bens previstos, há também disposições gerais que se aplicam indistintamente a todos eles, como a que determina o início da vigência do regime de bens, que coincidirá com a data do casamento, de acordo com o artigo $1639, \S 1^{\circ}$ do Código Civil.

O regime a ser adotado na união é aquele livremente escolhido pelos nubentes, através de pacto antenupcial, entretanto em caso em que estes não fazem a manifestação da vontade, ou sendo o pacto invalido, aplicasse ao casamento o chamado regime supletivo de vontade, previsto no artigo 1640 do Código Civil, que é o regime de comunhão parcial de bens, considerado por essa atribuição a espécie de regime mais importante do ordenamento.

Existe, ainda a liberdade de "estruturação do regime de bens, para os nubentes" (LOBO,2014 p. 288), não existe imposição legal para restrição da escolha de apenas um dos regimes previstos, podendo os nubentes de comum acordo mediante pacto antenupcial fundir tipos de regime ou ainda criar novo regime que não contrarie a lei vigente, nem seja manobra fraudar terceiro, expropriar bens, um contra o outro. Por ser esta convenção um ato solene, não pode ser estipulada por simples instrumento particular, o pacto é, facultativo, antecedente ao casamento e feito por escritura pública, como requisitos para validade do ato, sendo nula a convenção que não obedecer a tais formalidades.

Há no ordenamento jurídico a possibilidade dos cônjuges alterarem a modalidade anteriormente escolhida, conforme art. 1639, $\$ 2^{\circ}$ do Código Civil, que dispõe que a autorização para que seja alterado o regime de bens, observará alguns requisitos, concorrentes 
e cumulativos, como: autorização judicial, pedido motivado formulado por ambos os cônjuges, procedência das razões expostas por estes e ressalva dos direitos de terceiros, tal regra para alteração do regime de bens foi praticamente repetida pelo caput do art. 734 do Código de Processo Civil de 2015 “A alteração do regime de bens do casamento, observados os requisitos legais, poderá ser requerida, motivadamente, em petição assinada por ambos os cônjuges, na qual serão expostas as razões que justificam a alteração, ressalvados os direitos de terceiros".

\section{3 - REGIME DE SEPARAÇÃO LEGAL DE BENS}

O regime de separação de bens é diferente do regime de separação legal obrigatório de bens. O regime de separação de bens, chamado também de regime de separação convencional, é regulamentado pelo Código Civil nos artigos 1687 e 1688, os quais determinam que não haverá neste regime a comunicação de qualquer bem, anterior ou posterior à união, devendo cada cônjuge, de forma exclusiva, administrar seus bens, podendo inclusive cada cônjuge pode até alienar ou gravar com ônus real bens de sua propriedade, ainda que imóveis, não necessitando para tanto da anuência do cônjuge, para a aplicação dos efeitos de tal regime de bens é necessária a realização de um pacto antenupcial optando por esse regime, pacto este que deverá ser feito em cartório, observando os requisitos legais.

O regime de separação legal obrigatório de bens ou regime de bens compulsório ou obrigatório é previsto no artigo 1641 do Código Civil:

Art. 1641- É obrigatório o regime de separação de bens no casamento:

I das pessoas que o contraírem com inobservância das causas suspensivas da celebração do casamento;

II das pessoas maiores de setenta anos;

III de todos os que dependerem, para casar, de suprimento judicial.

O Código Civil instituiu o regime da separação de bens obrigatório para maiores de 60 anos e, tal dispositivo, foi alterado pela Lei $\mathrm{n}^{\circ} 12.344$ de 9 de dezembro de 2010, majorado para 70 anos, idade a partir da qual se torna obrigatório o regime da separação de bens no casamento.

Impele aos nubentes, nos casos específicos de seus três incisos, a adotar o regime de separação de bens previsto nos artigos 1687 e 1688 obrigatoriamente, sendo o objetivo da imposição de tal regime o impedimento da mistura patrimonial, preservando o interesse patrimonial individual dos cônjuges em determinadas núpcias, deixando revelar resquícios do caráter patrimonialista preconizado pelo Código Civil de 1916. 
Observando-se que no que concerne ao inciso I o caráter da imposição é a título de sansão pela não observância das causas suspensivas, nos demais incisos a intenção do legislador foi totalmente protecionista aos que ele considera "vulneráveis".

De acordo com o Enunciado 262 da III Jornada de Direito Civil que tem a seguinte redação: “A obrigatoriedade da separação de bens, nas hipóteses previstas nos incisos I e III do art. 1641 do Código Civil, não impede a alteração do regime, desde que superada a causa que o impôs", assim sendo, no caso do inciso I, não havendo mais razão para serem impostas as causas suspensivas e no caso do inciso III, se o nubente atingir certa idade que dispense o suprimento judicial, poderão os nubentes alterar a modalidade de regime de bens para aquela que melhor se adequar aos seus interesses, na hipótese do inciso II, como a condição imposta pelo legislador é imutável, o cônjuge septuagenário não terá liberdade para promover a alteração do regime de bens do seu matrimônio.

\section{4 - POPULAÇÃO IDOSA NO BRASIL}

De acordo com dados divulgados na página virtual do Ministério dos Direitos Humanos "uma em cada 9 pessoas no mundo tem 60 anos ou mais, e estima-se um crescimento para 1 em cada 5 por volta de 2050", afirma-se ainda que "em 2012, 810 milhões de pessoas têm 60 anos ou mais, constituindo $11,5 \%$ da população global. Projeta-se que esse número alcance 1 bilhão em menos de dez anos e mais que duplique em 2050, alcançando 2 bilhões de pessoas ou $22 \%$ da população global", refletindo uma melhora na qualidade de vida. Ainda de acordo com as informações do Ministério dos Direitos Humanos a pesquisa do IBGE revelou que em 20 anos (de 1991 a 2012) a população idosa no Brasil dobrou.

Em dados publicados pelo Portal Brasil em 02 de dezembro de 2016, o IBGE aponta que a população de idosos no Brasil correspondia no total da população 9,8\%, em 2005, e cresceu para $14,3 \%$, em 2015. Com base, ainda, na página do IBGE, as projeções tendem para o aumento cada vez maior da população idosa no Brasil.

De acordo com as projeções do IBGE, em estudos mais recentes publicados em 2018, a proporção atual de idosos é de 9,2\% ,19,2 milhões, mas em 2060 o percentual da população com 65 anos ou mais chegará a 25,5\%, 58,2 milhões de idosos, sendo assim um quarto da população total será idosa.

\section{5- DA AFRONTA A PRINCÍPIOS CONSTITUCIONAIS}


É flagrante a ofensa a princípios constitucionais do dispositivo do Código Civil que impõe um regime de bens obrigatório aos septuagenários. O princípio basilar da constituição, a Dignidade da Pessoa Humana, é o principal e mais ofendido pela norma. Eis a manifestação de Immanuel Kant (1986, p. 77) acerca da dignidade: "No reino dos fins tudo tem ou um preço ou uma dignidade. Quando uma coisa tem preço, pode-se pôr em vez dela qualquer outra como equivalente; mas quando uma coisa está acima de todo preço, e, portanto, não permite equivalente, então tem ela dignidade".

A intenção do constituinte ao focar no princípio da dignidade para base da Constituição Brasileira foi com a intenção de valorizar os seres humanos lhes dando a estima necessária, assim define Alexandre de Moraes (2002, p. 129):

A dignidade da pessoa humana é um valor espiritual e moral inerente à pessoa, que se manifesta singularmente na autodeterminação consciente e responsável da própria vida e que traz consigo a pretensão ao respeito por parte das demais pessoas, constituindo-se em um mínimo invulnerável que todo estatuto jurídico deve assegurar, de modo que apenas excepcionalmente possam ser feitas limitações ao exercício dos direitos fundamentais, mas sempre sem menosprezar a necessária estima que merecem todas as pessoas enquanto seres humanos.

Ainda nas palavras de Alexandre de Moraes (2002, p. 129), o princípio da Dignidade

da Pessoa Humana é não somente um direito fundamental, mas também um dever;

[...] princípio fundamental consagrado pela Constituição Federal da dignidade da pessoa humana apresenta-se em uma dupla concepção. Primeiramente, prevê um direito individual protetivo, seja em relação ao próprio Estado, seja em relação aos demais indivíduos. Em segundo lugar, estabelece verdadeiro dever fundamental de tratamento igualitário dos próprios semelhantes.

O princípio da dignidade evidencia a eleição da constituição da proteção dos valores sociais. Assim descreve Dimas Messias de Carvalho (2017, p. 62):

Ao conferir valor maior à proteção da pessoa humana, a Constituição federal, elegeu os valores sociais dominantes, como fundamentais, exigindo a aplicação dos princípios aos casos concretos para viabilizar o alcance da dignidade humana nas relações jurídicas, ultrapassando as concepções estritamente positivistas.

Maria Celina Bodin de Moraes (2005, p. 23) ao fazer uma análise das mudanças advindas da Constituição e do Código Civil, em seu texto "Família Democrática", classifica o que ainda fere princípios constitucionais e precisa ser alterado, incluído nessas alterações a imposição do regime de bens obrigatório aos idosos;

[...]no que se refere à redução de liberdade, diz respeito à obrigatoriedade do regime de bens para as pessoas maiores de 60 anos, previsto no art. 1.641, II. Claramente, o objetivo do legislador foi protecionista; no entanto, não se justifica a limitação da liberdade de escolha de pessoas plenamente capazes, a não ser os interesses patrimoniais dos parentes, os quais, justamente por serem patrimoniais, devem ceder diante do direito à livre opção do nubente.

Observando a conceituação do princípio da dignidade resta claro a ofensa ao princípio pelo dispositivo que impõe o regime obrigatório aos maiores de setenta anos, como 
leciona Carlos Roberto Gonçalves (2017, página 639): “A imposição do regime da separação legal, nesses casos, é de duvidosa constitucionalidade, por ofender o princípio da dignidade humana".

Autores defendem ainda que a imposição do regime de bens aos septuagenários fere não somente o princípio da dignidade humana, mas, ainda, uma gama de outros princípios correlatos a este, como a autonomia privada.

O princípio da dignidade humana é o mais universal de todos os princípios. É um macroprincípio do qual se irradiam todos os demais: liberdade, autonomia privada, cidadania, igualdade, uma coleção de princípios éticos. (DIAS, 2012, p. 62).

A autonomia privada é conceituada por Ana Prata (1982, p. 11) nos seguintes termos;

A autonomia privada ou liberdade negocial traduz-se, pois no poder reconhecido pela ordem jurídica ao homem, prévia e necessariamente qualificado como conceito jurídico, de juridicizar a sua atividade (designadamente a sua atividade econômica), realizando livremente negócios jurídicos e determinando os respectivos efeitos.

Branco Moreira (2011, p. 134) amplia o conceito de autonomia privada afirmando que não se trata somente de questões patrimoniais, mas também de questões existenciais, sendo a autonomia privada ou estipulação negocial um direito inerente ao ser humano, sendo plenamente possível sua aplicação no Direito de Família, "A autonomia privada perdeu a sua conotação exclusivamente patrimonial com a incidência de direitos fundamentais nas relações privadas, passando a ser aplicada igualmente nas relações extrapatrimoniais, como as do âmbito do Direito de Família."

$\mathrm{O}$ desrespeito a princípios perpassa também pela liberdade. $\mathrm{O}$ brasileiro tem assegurado pela constituição a liberdade no âmbito familiar, sendo assim, possui livre iniciativa para constituir família e organiza-la sem a intervenção do Estado.

O dispositivo afronta, ainda, substancialmente outro princípio basilar da Constituição, qual seja a igualdade, artigo $5^{\circ}$ da $\mathrm{CF} / 88$. A igualdade garante ao indivíduo isonomia quanto a proteção e garantia de direitos, não podendo as diferenças naturais do ser humano não pode legitimar uma diferenciação negativa ou restritiva dada pelo legislador, devendo ser observadas as peculiaridades para melhor tutela do direito individual

Muitos doutrinadores, como Paulo Lôbo (2014, p.294-295), defendem que a determinação é, ainda, inconstitucional, além de se partir de uma presunção de incapacidade, que somente pode ser determinada por decisão judicial.

Além de sua inconsistência moral e inconstitucional, a norma que impede aos maiores de 70 anos liberdade de escolha do regime de bens cria, indiretamente, uma 
incapacidade de exercício de direito [...] A idade avançada, por si só, não é geradora da incapacidade civil. A norma é preconceituosa, na medida em que veda o direito ao amor, ao afeto matrimonial e à expressão plena dos sentimentos da pessoa idosa.

Defendem também a inconstitucionalidade da norma os autores Cristiano Chaves de Farias e Nelson Rosenvald (2010, p.244-245), bem como consideram uma forma de constrangimento não só pessoal como social para o nubente maior de 70 anos:

Efetivamente, trata-se de dispositivo legal inconstitucional [...], por reduzir a sua anatomia como pessoa e constrangê-lo pessoalmente e socialmente, impondo uma restrição que a norma constitucional não previu.

No tocante da inconstitucionalidade manifesta-se também Maria Berenice Dias no sentido de que o idoso é negligenciado pela legislação imputando-lhe uma incapacidade presumida que totalmente incompatível com as regras do ordenamento brasileiro que tem especial rigor quando trata da capacidade da pessoa.

A limitação, além de odiosa, é inconstitucional, pois, ao se falar no estado da pessoa, toda cautela é pouca. A plena capacidade é adquirida quando do implemento da maioridade e só pode ser afastada em situações extremas e por meio do processo judicial de interdição, que dispõe de rito especial. (DIAS, 2008, p. 4)

Além da doutrina algumas jurisprudências também apontam para a inconstitucionalidade na norma:

INCIDENTE DE INCONSTITUCIONALIDADE - DIREITO CIVIL CASAMENTO - CÔNJUGE MAIOR DE SESSENTA ANOS - REGIME DE SEPARAÇÃO OBRIGATÓRIA DE BENS - ART. 258, PARÁGRAFO ÚNICO DA LEI 3.071/16 - INCONSTITUCIONALIDADE - VIOLAÇÃO DOS PRINCÍPIOS DA IGUALDADE E DA DIGNIDADE HUMANA. - É inconstitucional a imposição do regime de separação obrigatória de bens no casamento do maior de sessenta anos, por violação aos princípios da igualdade e dignidade humana.

(TJ-MG - ARG: 10702096497335002 MG, Relator: José Antonino Baía Borges, Data de Julgamento: 12/03/2014, Órgão Especial / ÓRGÃO ESPECIAL, Data de Publicação: 21/03/2014)

Diante do inconformismo com a norma, considerada por muitos inconstitucional, existe um projeto de lei para modificação do artigo 1641, II do Código Civil, o projeto de Lei do Senado $n^{\circ} 760$ de 2015, que pretende revogar a obrigatoriedade do regime de separação de bens no casamento da pessoa com mais de setenta anos, com base na doutrina pela inconstitucionalidade, nos princípios constitucionais, nos direitos garantidos pelo Estatuto do Idoso e, ainda, no entendimento dos juristas da I Jornada de Direito Civil do Conselho da Justiça Federal, mediante Enunciado (125):

125 - Proposição sobre o art. 1.641, inc. II: Redação atual: 'da pessoa maior de sessenta anos'. Proposta: Revogar o dispositivo. Justificativa: A norma que torna obrigatório o regime de separação absoluta de bens em razão da idade dos nubentes (qualquer que seja ela) é manifestamente inconstitucional, malferindo o princípio da dignidade humana, um dos fundamentos da República, inscrito no pórtico da Carta Magna (art. $1^{\circ}$, inc. III da CF). Isso porque introduz preconceito quanto às pessoas idosas que somente por ultrapassarem determinado patamar etário, passam a gozar de presunção absoluta de incapacidade para alguns atos, como contrair matrimônio 
pelo regime de bens que melhor consultar seus interesses. (Jornadas de Direito Civil - I, III, IV e V - Enunciados Aprovados/Coordenador científico Ministro Ruy Rosado de Aguiar Júnior. - Brasília: Conselho da Justiça Federal. Centro de Estudos Judiciário, 2012)

\section{6 - APLICAÇÃO DA SUMÚLA 377 DO STF}

Em face de todas as críticas, existe a mitigação da restrição imposta pelo legislador aos septuagenários, haja vista a aplicação da Súmula 337 do Supremo Tribunal Federal, que passou a considerar que os bens adquiridos pelo esforço em comum, quando na comunhão de separação legal, comunicam-se, tal súmula foi editada no ano de 1964, em resposta a jurisprudências que já lutavam contra a imposição do dispositivo.

A súmula não tem efeito vinculante, entretanto é parâmetro para todo o Judiciário e orienta a regulamentação existente nos Códigos de Normas do Extrajudicial dos Estados da Federação. Advindo o Código Civil de 2002 a súmula continuou a produzir efeitos como mencionado por Paulo Lôbo (2014, p. 295-296) "Permanece aplicável a Súmula 377 do STF, com o seguinte enunciado: 'No regime de separação legal de bens comunicam-se os adquiridos na constância do casamento'. Em seus efeitos práticos, a Súmula converte o regime legal de separação em regime de comunhão parcial.”

A súmula 377, que originou-se da interpretação dada pelo Tribunal ao artigo 259 do Código Civil de 1916, e objetivava reduzir os rigores do regime de separação legal, por ser ainda vigente, deixa claro que a preocupação do STF em proteger quem de boa-fé contrair matrimônio com septuagenários.

Alguns doutrinadores entendem que a presunção de comunhão da súmula é absoluta “A presunção de comunhão da Súmula é absoluta, não se admitindo discussão sobre terem sido adquiridos os bens com a participação efetiva ou não de ambos os cônjuges." (LÔBO, 2014, p. 296).

Em sentido contrário existe a afirmação que a presunção de comunhão traz enriquecimento ilícito, devendo então haver comprovação do empenho comum para constituição do patrimônio conjugal. É o que defende Amim Seba Taissum em seu artigo publicado na revista Rios eletrônica em 2012.

A presunção de esforço comum por parte de ambos os cônjuges, indubitavelmente, traz à toda sociedade prejuízos de dificílima reparação, fato que incentivaria, institucionalmente, o famoso e tão reprovável Golpe do Baú.

Em breve pesquisa jurisprudencial é possível encontrar decisões que corroboram com as duas linhas de pensamento, mas a maioria segue o entendimento da presunção de 
comunhão. A corrente que defende que deve haver comprovação de contribuição para construção do patrimônio comum:

AGRAVO DE INSTRUMENTO. DIREITO SUCESSÓRIO. AÇÃO DE INVENTÁRIO. EXCLUSÃO DA COMPANHEIRA DO INVENTARIADO DO POLO ATIVO DA PRESENTE DEMANDA. Não preenchimento dos requisitos referentes à meação ou à vocação hereditária. Muito embora a agravante tenha comprovado que conviveu com o autor da herança de agosto de 2008 até falecimento deste, em janeiro de 2010, é certo que em razão de o falecido já contar com 80 anos de idade no momento da lavratura da escritura pública de união estável, aplicável ao caso a regra do art. 1641, II do Código Civil, que impõe ao casamento (e união estável) dos maiores de 70 anos, o regime de separação de bens. Ainda que assim não fosse, o art. 1829, I do Código Civil, também aplicável às uniões estáveis, estabelece que na sucessão legítima o companheiro não concorrerá com os descendentes na hipótese de separação obrigatória de bens, como é o caso dos autos. Registre-se, por fim, que, ao contrário do que afirma a recorrente, as provas trazidas aos autos, não demonstram qualquer concorrência desta para a aquisição de bens descritos na inicial, não havendo que se cogitar, portanto, de aplicação da Súmula 377 STF ao caso vertente. RECURSO A QUE SE NEGA PROVIMENTO.

(TJ-RJ - AI: 00260511420218190000, Relator: Des(a). CLÁUDIO LUIZ BRAGA DELL'ORTO, Data de Julgamento: 12/05/2021, DÉCIMA OITAVA CÂMARA CÍVEL, Data de Publicação: 13/05/2021)

E a corrente que corrobora com o entendimento que a presunção de comunhão é

absoluta:

APELAÇÃO CÍVEL. AÇÃO DE DIVÓRCIO LITIGIOSO. CASAMENTO REALIZADO NA VIGÊNCIA DO CÓDIGO CIVIL DE 1916, PELO REGIME DA SEPARAÇÃO OBRIGATÓRIA DE BENS. PARTILHA. POSSIBILIDADE. O regime obrigatório da separação de bens, previsto no parágrafo único do art. 258 do CCB/1916, vigente à época do matrimônio, atual art. 1.641 do CCB/2002, não se confunde com o regime facultativo da separação de bens, previsto nos arts. $1.687 \mathrm{e}$ 1.688 do mesmo diploma legal em vigor. Na hipótese dos autos, em que o regime adotado foi o da separação legal (obrigatória), os bens adquiridos na constância do casamento de forma onerosa devem ser partilhados em proporção igualitária, conforme Súmula no 377 do STF. Diante disso, correta a partilha, na proporção de $50 \%$ para cada litigante, do imóvel descrito nos autos, pois, ainda que não haja participação financeira efetiva do cônjuge na aquisição do patrimônio, presume-se o esforço comum, devendo ocorrer a divisão dos bens igualitariamente após a dissolução da sociedade conjugal, eis que não comprovada nenhuma causa de exclusão. Sentença confirmada. APELO DESPROVIDO.

(Apelação Cível No 70074640822, Sétima Câmara Cível, Tribunal de Justiça do RS, Relator: Sandra Brisolara Medeiros, Julgado em 27/09/2017). (TJ-RS - AC: 70074640822 RS, Relator: Sandra Brisolara Medeiros, Data de Julgamento: 27/09/2017, Sétima Câmara Cível, Data de Publicação: Diário da Justiça do dia 29/09/2017)

O entendimento majoritário do STJ é que o esforço comum a que se refere à súmula 377 do STF é presumido, não sendo necessária a comprovação:

EMENTA: AGRAVO DE INSTRUMENTO - INVENTÁRIO - CASAMENTO SEPARAÇÃO OBRIGATÓRIO DE BENS - PARTILHA - MEAÇÃO DA COMPANHEIRA SOBREVIVENTE - OBEDIÊNCIA A SÚMULA 377 DO STF - RECURSO DESPROVIDO. 1. A partilha, mediante meação do cônjuge sobrevivente, dos bens adquiridos na constância de casamento erigido sob a forma de separação legal de bens (art. 258, parágrafo único, II, do CC/1916) não exige a comprovação ou demonstração de comunhão de esforços na formação desse 
patrimônio, o qual é presumido, à luz do entendimento cristalizado na Súmula n. 377/STF. 2. Negar provimento ao recurso."(fl. 264) Em suas razões recursais, a parte recorrente aponta violação do art. 1.829, inciso I, do Código Civil de 2002, e divergência jurisprudencial, sustentando, em síntese, a superação do entendimento da Súmula 377 do STF, somente sendo permitida a meação ao cônjuge casado no regime de separação legal desde que demonstre o esforço comum na aquisição do patrimônio na constância do casamento. Não foram apresentadas contrarrazões (fl. 331). É o relatório. No que tange à alegada violação do art. 1.829 , inciso $\mathrm{I}$, do Código Civil de 2002, verifica-se que a tese de superação ou relativização da aplicação da Súmula 377/STF para somente permitir a meação desde que demonstrado o esforço comum na aquisição do patrimônio não foi apreciado pelo Tribunal a quo, tampouco foram opostos embargos declaratórios para sanar eventual omissão. Dessa forma, à falta do indispensável prequestionamento, incide, por analogia, o óbice das Súmulas 282 e 356 do STF. Nesse sentido: "AGRAVO INTERNO NO AGRAVO EM RECURSO ESPECIAL - AÇÃO ANULATÓRIA DE ARREMATAÇÃO JUDICIAL - DECISÃO MONOCRÁTICA QUE NEGOU PROVIMENTO AO RECLAMO. INSURGÊNCIA DOS REQUERENTES. 1. Incide a Súmula 282/STF quando a tese recursal não foi objeto de debate pela instância ordinária e tampouco suscitada em embargos de declaração. Nesta instância especial, o requisito do prequestionamento é indispensável mesmo em questões de ordem pública. 2. A reforma do aresto a quo, para reconhecer a nulidade da arrematação, ensejaria o reexame de fatos e provas, o que encontra óbice na Súmula 7/STJ. 3. O entendimento do STJ é no sentido de que o preço vil só se caracteriza quando a arrematação não alcançar, ao menos, a metade do valor da avaliação, o que não foi o caso dos autos. Incidência da Súmula 83/STJ. 3.1. Para rever as conclusões das instâncias ordinárias sobre a questão seria necessário a incursão no acervo fáticoprobatório, prática vedada pela Súmula 7/STJ. 4. Agravo interno desprovido."

(AgInt no AREsp 1552557/GO, Rel. Ministro MARCO BUZZI, QUARTA TURMA, julgado em 09/03/2020, DJe 16/03/2020,g.n.) Diante do exposto, nos termos do art. $255, \S 4^{\circ}$, I, do RISTJ, não conheço do recurso especial. Publiquese. Brasília, 18 de agosto de 2020. Ministro RAUL ARAÚJO Relator (STJ - REsp: 1629865 MG 2016/0259185-0, Relator: Ministro RAUL ARAÚJO, Data de Publicação: DJ 26/08/2020)

\section{7 - CONSIDERAÇÕES FINAIS}

Independente da definição adotada, os regimes de bens existentes no Direito Civil Brasileiro têm como objetivo a regulamentação dos efeitos econômicos que inevitavelmente advirão das relações conjugais. Assim sendo, objetivando a segurança jurídica, torna-se necessária a existência de um conjunto de normas jurídicas que regulamentem os regimes de bens possibilitando aos nubentes a melhor escolha da sua esfera de autonomia privada.

Após toda explanação e análise sobre a imposição de regime de bens aos nubentes maiores de 70 anos, frente aos princípios constitucionais, é evidente a inconstitucionalidade da norma. Isso se deve ao fato que não devem ser aplicadas normas que conflitem com a Constituição, lei maior do ordenamento.

Conforme análise doutrinária entende-se em sua maioria que o dispositivo 1641, II do Código Civil afronta princípios constitucionais tais como a dignidade da pessoa humana, 
artigo $1^{\circ}$, III da CF/88, que é princípio basilar da Carta Magna, a liberdade, artigo $5^{\circ}$, I da $\mathrm{CF} / 88$, por ser cerceado o livre direito de escolha do regime de bens em que se casará o maior de 70 anos, a autonomia privada, princípio implícito que dá a liberdade negocial respeitando a esfera privada da pessoa, e, ainda, o princípio da igualdade, artigo $5^{\circ}$, caput da $\mathrm{CF} / 88$, subjulgando, assim, o septuagenário e lhe impondo limites com base em uma presunção ilegal de sua capacidade civil.

A súmula 377, que teve origem na interpretação dada pelo STF ao artigo 259 do Código Civil de 1916, e objetivava reduzir os rigores do regime de separação legal, e foi editada em resposta a jurisprudência que já lutava contra a imposição do dispositivo, mitigando a restrição imposta pelo legislador, por ser ainda vigente, deixa claro que a preocupação do STF em proteger quem de boa-fé contrair matrimônio com septuagenários.

Verifica-se, por fim, observando os dados da pesquisa realizada, que a população idosa brasileira vive uma realidade nova onde a expectativa de vida cresceu consideravelmente e por consequência cresceu, também, o número de pessoa com 70 anos ou mais, tornando o dispositivo 1641, II, do código Civil demasiadamente incompatível com a realidade.

Com a base teórica da pesquisa conclui-se que não faz sentido a manutenção da norma, que impõe tal regime de bens, sendo latente a necessidade da declaração da inconstitucionalidade do dispositivo que impõe um regime de bens ao septuagenário, pura e simplesmente com base em sua idade. Foi possível concluir, ainda, que o dispositivo, objeto do estudo é incompatível com a atual realidade brasileira, entendo então que é necessária a revogação do inciso II do artigo 1641 do Código civil.

\section{REFERÊNCIAS BIBLIOGRÁFICAS}

BEVILÁQUA, Clóvis. Código Civil dos Estados Unidos do Brasil Comentado. 7. ed. Rio de Janeiro: Francisco Alves, 1945, v. 2.

BRANCO, Gerson Luiz Carlos; MOREIRA, José Alberto Marques. Autonomia privada nas relações de direito de família. In: SEMINÁRIO NACIONAL DE DIMENSÕES MATERIAIS E EFICACIAIS DOS DIREITOS FUNDAMENTAIS, 1., 2011, Chapecó: Editora Unoesc, 2011. Disponível em: <http://editora.unoec.edu.br/index.php/seminarionacionaldedimensoes/article/view/959>. Acesso em: 10 de setembro de 2021. 
BRANCO, Gerson Luiz Carlos; MOREIRA, José Alberto Marques. Autonomia Privada nas Relações do Direito de Família. v. 1, 2011. Chapecó: Editora Unoesc, 2011. Disponível em: < http://editora.unoesc.edu.br/index.php/seminarionacionaldedimensoes/article/view/959 >. Acesso em: 10 de setembro 2021.

BRASIL. Instituto Brasileiro de Geográfica e Estatística. Projeção da população 2018: número de habitantes do país deve parar de crescer em 2047. Publicado em 25 de julho de 2018. Disponível em: < https://agenciadenoticias.ibge.gov.br/agencia-sala-de-imprensa/2013agencia-de-noticias/releases/21837-projecao-da-populacao-2018-numero-de-habitantes-dopais-deve-parar-de-crescer-em-2047>. Acesso em 14 de setembro de 2021.

BRASIL. Instituto Brasileiro de Geográfica e Estatística. Projeção da população do Brasil e das Unidades da Federação. <https://www.ibge.gov.br/apps/populacao/projecao/index.html>. Acesso em 14 de setembro de 2021.

BRASIL. Lei 10.741 de 2003. Estatuto do Idoso. Disponível em:< http://www.planalto.gov.br/CCivil_03/leis/2003/L10.741.htm>. Acesso em 14 de setembro de 2021.

BRASIL. Projeto de Lei do Senado $\mathbf{n}^{\circ} \mathbf{7 6 0}$, de 2015. Disponível em: <https://www25.senado.leg.br/web/atividade/materias/-/materia/124248>. Acesso em 09 de setembro de 2021.

BRASIL. Superior Tribunal de Justiça. Embargos de divergência contra acórdão prolatado pela Terceira Turma, de relatoria do Ministro Ricardo Villas Bôas. Cueva Disponível em: < https://stj.jusbrasil.com.br/jurisprudencia/506522859/edv-nos-embargos-dedivergencia-em-resp-edv-nos-eresp-1593663-df-2016-0046728-0/decisao-monocratica506522868>. Acesso em: 12 de setembro de 2021.

CARVALHO, Dimas Messias de. Direito das Famílias. 5. ed. São Paulo: Saraiva, 2017.

Código Civil de 2002, Disponível em: <http://www.planalto.gov.br/ccivil_03/leis/2002/L10406.htm>. Acesso em 10 de setembro de 2021.

COELHO, Fábio Ulhoa. Curso de Direito Civil: família, sucessões. $5^{\mathrm{a}}$ ed. São Paulo: Saraiva,2012.

CONSTITUIÇÃO DA REPÚBLICA FEDERATIVA DO BRASIL DE 1988. Disponível em: $<$ http://www.planalto.gov.br/ccivil_03/constituicao/constituicao.htm>. Acesso em 12 de setembro de 2021.

DIAS, Maria Berenice. Amor não tem idade. Disponível em:< http://www.mariaberenice.com.br/uploads/5_-_amor_n\%E3o_tem_idade.pdf>. Acesso em 10 de setembro de 2021.

DIAS, Maria Berenice. Manual de Direito das Famílias. $2^{a}$ edição revista. Porto Alegre: Livraria do Advogado Editora, 2005. 
DIAS, Maria Berenice. Manual de direito das famílias. 9 ed.rev. atual e ampl. São Paulo: Editora Revista dos Tribunais, 2013.

FARIAS, Cristiano Chaves de; ROSENVALD, Nelson. Direitos das famílias - Vol.6 - 7 . Ed. São Paulo: Saraiva, 2015.

GONÇALVES, CARLOS ROBERTO. Direito Civil Esquematizado. São Paulo, Saraiva, 4. ed., 2017.

IBDFAM. Revista brasileira de direito das famílias e sucessões. Belo Horizonte: IBDFAM,2011, v. 10.

KANT, Immanuel. Fundamentação da metafísica dos costumes. (Trad. Paulo Quintela). 3. ed.São Paulo: Abril Cultural, 1986. LÔBO, Paulo. Direito civil: famílias - 5. Ed. - São Paulo: Saraiva, 2014.

MADALENO, Rolf. Curso de direito de família. 5. ed. rev., atual. e ampl. Rio de Janeiro: Forense, 2013.

MARMELSTEIN, George. Curso de Direitos Fundamentais. 4 ed. São Paulo: Atlas, 2013.

MIRANDA, Pontes de. Tratado de direito de família. Campinas: ed.Bookseller, 2001.

MONTEIRO, Whashington de Barros. SILVA, Regina Beatriz Tavares. Curso de Direito Civil. Vol. 2. $41^{\mathrm{a}}$ ed. São Paulo: Saraiva, 2011.

MORAES, Alexandre de. Constituição do Brasil interpretada e legislação constitucional. São Paulo: Atlas, 2002. Alexandre de. Direito Constitucional. 26. ed. São Paulo: Atlas, 2010.

MORAES, Maria Celina Bodin de. A Família Democrática. Disponível em: < http://www.ibdfam.org.br/_img/congressos/anais/31.pdf>. Acesso em 12 de setembro de 2021.

ONU. A ONU e as pessoas idosas. 2016. Disponível em:<https://brasil.un.org/pt-br/67772em-2050-idosos-serao-dois-bilhoes-de-pessoas-ou-20-de-toda-populacao-mundial-diz-onu>. Acesso em: 12 de setembro de 2021

PRATA, Ana. A tutela constitucional da autonomia privada. Lisboa: Livraria Almedina, 1982.

Superior Tribunal de Justiça. Embargos de divergência contra acórdão prolatado pela Terceira Turma, de relatoria do Ministro Ricardo Villas Bôas. Cueva Disponível em: < https://stj.jusbrasil.com.br/jurisprudencia/506522859/edv-nos-embargos-de-divergencia-emresp-edv-nos-eresp-1593663-df-2016-0046728-0/decisao-monocratica-506522868>. Acesso em: 10 de setembro de 2021.

Superior Tribunal de Justiça. REsp:16298665. Julgado em 18 de agosto de 2020. Relator: Raul Araújo. Disponível em: <https://stj.jusbrasil.com.br/jurisprudencia/919858313/recurso- 
especial-resp-1629865-mg-2016-0259185-0/decisao-monocratica-919858323>. Acesso em 10 de setembro de 2021.

Tribunal de Justiça de Minas Gerais. ARG: 10702096497335002 MG. Julgado em 12 de março de 2014. Relator: José Antonino Baía Borges. Disponível em:< https://tjmg.jusbrasil.com.br/jurisprudencia/119528602/arg-inconstitucionalidade-arg-

10702096497335002-mg/inteiro-teor-119528708>. Acesso em: 10 setembro de 2021

Tribunal de Justiça do Rio de Janeiro. AI: 002605114202218190000. Julgado em 12 de maio de 2021. Relator: Cláudio Luiz Braga Dell'orto. Disponível em: <https://tjrj.jusbrasil.com.br/jurisprudencia/1206918071/agravo-de-instrumento-ai-

260511420218190000>. Acesso em 12 de setembro de 2021.

Tribunal de Justiça do Rio Grande do Sul. AC: 70074640822 . Julgado em 27 de setembro de 2017. Relatora: Sandra Brisolara Medeiros. Disponível em: < https://tjrs.jusbrasil.com.br/jurisprudencia/504675664/apelacao-civel-ac-70074640822-rs>. $\quad$ Acesso em: 12 de setembro de 2021.

TAISSUM, Seba Amin. O regime de separação obrigatória de bens: restrições à súmula 377 do supremo tribunal federal. Paulo Afonso, DEZ/2012, Rios Eletrônica- Revista Científica da FASETE. Disponível em: https://www.unirios.edu.br/revistarios/media/revistas/2012/6/o_regime_de_separacao_obrigat oria_de_bens.pdf >. Acessado em 14 de setembro de 2021.

VILLELA, João Baptista. Liberdade e família. Belo Horizonte: Faculdade de Direito da UFMG, 1980. 